\title{
The Effect of 17-alpha Hydroxyprogesterone Caproate on the Risk of Gestational Diabetes in Singleton or Twin Pregnancies
}

\begin{abstract}
Cynthia Gyamfi, MD, Amanda L. Horton, MD, Valerija Momirova, MS, Dwight J. Rouse, MD, Steve N. Caritis, MD, Alan M. Peaceman, MD, Anthony Sciscione, DO, Paul J. Meis, MD, Catherine Y. Spong, MD, Mitchell Dombrowski, MD, Baha Sibai, MD, Michael W. Varner, MD, Jay D. lams, MD, Brian M. Mercer, MD, Marshall W. Carpenter, MD, Julie Lo, MD, Susan M. Ramin, MD, Mary Jo O'Sullivan, MD, Menachem Miodovnik, MD, and Deborah Conway, MD for the Eunice Kennedy Shriver National Institute of Child Health and Human Development Maternal-Fetal Medicine Units Network, Bethesda, MD

From the Departments of Obstetrics and Gynecology at Columbia University, New York, NY; University of North Carolina, Chapel Hill, NC; University of Alabama at Birmingham, Birmingham, AL; University of Pittsburgh, Pittsburgh, PA; Northwestern University, Chicago, IL; Drexel University, Philadelphia, PA; University of Utah, Salt Lake City, UT; The Ohio State University, Columbus, $\mathrm{OH}$; Case Western Reserve University, Cleveland, OH; Wayne State University, Detroit, Ml; Brown University, Providence, RI; University of Texas Southwestern Medical Center, Dallas, TX; University of Texas Health Science Center at Houston, Houston, TX; Wake Forest University Health Sciences, Winston-Salem, NC; University of Tennessee, Memphis, TN; University of Miami, Miami, FL; University of Cincinnati, Cincinnati, $\mathrm{OH}$; University of Texas at San Antonio, San Antonio, TX; and The George Washington University Biostatistics Center, Washington, DC and the Eunice Kennedy Shriver National Institute of Child Health and Human Development, Bethesda, MD
\end{abstract}

\section{Abstract}

Objective-To compare the rates of gestational diabetes (GDM) among women who received serial doses of 17 alpha hydroxyprogesterone caproate (17-OHPC) versus placebo.

Study Design-Secondary analysis of two double-blind randomized placebo-controlled trials of 17-OHPC given to women at risk for preterm delivery. The incidence of GDM was compared between women who received 17-OHPC or placebo.

Results-We included 1094 women; 441 had singleton and 653 had twin gestations. Combining the two studies, 616 received 17-OHPC and 478 received placebo. Among singleton and twin pregnancies, rates of GDM were similar in women receiving $17-\mathrm{OHPC}$ versus placebo $(5.8 \%$ vs. $4.7 \%, \mathrm{p}=0.64$ and $7.4 \%$ vs $7.6 \%, \mathrm{p}=0.94$, respectively). In the multivariable model, progesterone was not associated with GDM (adjusted odds ratio (adj OR) 1.04, 95\% confidence interval (CI) 0.62 to 1.73$)$.

Conclusion-Weekly administration of 17-OHPC is not associated with higher rates of gestational diabetes in either singleton or twin pregnancies.

(C) 2009 Mosby, Inc. All rights reserved.

Corresponding Author: Cynthia Gyamfi, MD, Columbia University Medical Center, Department of Obstetrics and Gynecology, Division of Maternal-Fetal Medicine, 622 West $168^{\text {th }}$ Street, PH-16, New York, NY 10032.cg2231@ columbia.edu.

Publisher's Disclaimer: This is a PDF file of an unedited manuscript that has been accepted for publication. As a service to our customers we are providing this early version of the manuscript. The manuscript will undergo copyediting, typesetting, and review of the resulting proof before it is published in its final citable form. Please note that during the production process errors may be discovered which could affect the content, and all legal disclaimers that apply to the journal pertain.

Presented at the Society for Maternal-Fetal Medicine, January 31, 2009, San Diego, CA. 


\section{Keywords}

17- $\alpha$ hydroxy progesterone caproate; gestational diabetes; singletons; twins

\section{INTRODUCTION}

Preterm birth (PTB), defined as birth between $20^{0 / 7}$ to $36^{6 / 7}$ weeks gestation, remains a major cause of neonatal morbidity and mortality worldwide. In the United States, the rate of PTB has progressively increased from 9 percent to 12 percent over the past two decades. ${ }^{1}$ Public health campaigns and medical interventions including trials of decreased maternal activity, home uterine activity monitoring, tocolytic therapy, and antibiotic therapy targeted against various organisms, have yet to produce an effective and consistent model for PTB prevention. ${ }^{2}$ The use of progestins to prevent PTB has regained popularity after two randomized controlled trials in 2003 showed a reduction in preterm birth among women at high risk for PTB. ${ }^{3,4}$ The American College of Obstetricians and Gynecologists (ACOG) and the Society for MaternalFetal Medicine suggest offering progesterone to women with a singleton gestation and a prior PTB and state that other indications for the use of this drug need further investigation. ${ }^{5}$

With increasing use of progestagens throughout pregnancy, there should be ongoing evaluation of the potential impact of these medications on both mother and fetus. Throughout pregnancy, metabolic changes occur to meet the needs of the growing fetus. Several essential pregnancy hormones including progesterone, cortisol, human placental lactogen, and estrogen affect insulin homeostasis and may influence the frequency of gestational diabetes (GDM). Progesterone is thought to exhibit diabetogenic properties through a reduction in glucose transporter 4 expressions or by impairing the normal $\beta$ cell adaptive response of enhanced insulin secretion. ${ }^{6}$ Animal studies have demonstrated that progesterone plays a key role in pancreatic function and in signaling insulin release. ${ }^{7}$ These observations raise the question of whether progesterone administration during pregnancy increases the risk of gestational diabetes. ${ }^{8}$

Gestational diabetes, affecting roughly $5 \%$ of women, is one of the most common diseases during pregnancy and is associated with adverse perinatal outcomes. ${ }^{9}$ It is also thought to be slightly more common in twin pregnancies, although data are conflicting. ${ }^{10} \mathrm{~A}$ recent cohort study examining the association of treatment with 17 alpha hydroxyprogesterone caproate (17OHPC) with gestational diabetes in singleton pregnancies found a significantly higher rate of gestational diabetes in women receiving 17-OHPC compared with patients with a prior PTB who did not receive this intervention. ${ }^{8}$ Thus, our purpose was to evaluate the effect of prophylactic 17-OHPC on the rate of GDM in both singleton and twin gestations.

\section{MATERIALS AND METHODS}

This is a secondary analysis of two randomized, double-blinded, placebo-controlled clinical trials of 17-OHPC to prevent recurrent PTB in singleton pregnancies and to prevent PTB in twin pregnancies. Full details of the methods and study design have been previously reported. 3,11 In the prevention of recurrent PTB trial, 463 women with at least one previous spontaneous preterm delivery were randomized using a 2:1 randomization scheme to receive weekly injections of 17-OHPC or placebo beginning at 16 to $20^{6 / 7}$ weeks gestation and continuing until $36^{6 / 7}$ weeks gestation. In the prevention of PTB in twin pregnancies, 661 women were randomized to receive weekly injections of 17 -OHPC or placebo beginning at 16 to $20^{6 / 7}$ weeks gestation and continuing until delivery or $34^{6 / 7}$ weeks gestation. Women from the singleton trial with a pre-pregnancy diagnosis of diabetes (17 cases), unknown GDM status (1 case) or who were lost to follow-up (4 cases) were excluded from this analysis, resulting in 293 and 
148 patients in the 17-OHPC and placebo groups, respectively. No women in the twin trial had pre-existing diabetes as it was a trial exclusion. Women with GDM status unknown ( 2 cases) or who were lost to follow-up (6 cases) were excluded from the analysis, leaving 323 and 330 patients in the 17-OHPC and placebo groups, respectively. Gestational ages for all participants in both studies were confirmed by first or second trimester sonogram.

The outcome of interest in this analysis was the rate of gestational diabetes in singleton or twin pregnancies in women who received 17-OHPC. The presence of gestational diabetes was based upon documentation in the medical record. GDM was listed as either present or absent; results of the glucose screen and 3 hour oral glucose tolerance test were not reviewed to verify the diagnosis. Because this is a secondary analysis, criteria for diagnosis of GDM were not predefined. However, the centers that participated in the original study use similar guidelines to diagnose gestational diabetes. The association of patient characteristics and GDM were evaluated using the Wilcoxon test, for continuous variables, and $\chi^{2}$ test for categorical variables. The relationship between 17-OHPC and GDM was further investigated using a multivariable logistic regression, controlling for variables that may influence the presence of GDM including maternal age, body mass index $(\mathrm{BMI}) \geq 30$, twin gestation, and African-

American race. Maternal age was evaluated as a continuous variable; the odds ratio for this variable reflects the incremental risk of developing GDM per year of maternal age. Odds ratios (OR) and 95\% confidence intervals (CI) for GDM were determined. Nominal statistical significance was set at a p-value less than 0.05 .

\section{RESULTS}

In this analysis, 1094 women with known GDM status were included [Table 1]. Overall, the rate of gestational diabetes was $5.4 \%$ in singleton pregnancies and $7.5 \%$ in twin pregnancies. In the prevention of recurrent PTB trial in singleton pregnancies, the maternal demographic characteristics between groups were similar except for number of prior preterm deliveries.

As shown in Figure 1, there was no difference in rates of GDM in women receiving 17-OHPC versus placebo in either group (singletons, $5.8 \%$ vs. $4.7 \%$, RR $1.23,95 \% \mathrm{CI}(0.52,2.89)$, $\mathrm{p}=0.64$; twins $7.4 \%$ vs. $7.6 \%$, RR $0.98,95 \% \mathrm{CI}(0.57,1.68), \mathrm{p}=0.94)$. Maternal age and body mass index (BMI) were significantly associated with GDM ( $p<0.001$, and $p<0.001$, respectively). The association between GDM and 17-OHPC use was assessed controlling for maternal age, study type (singleton/twin) and prepregnancy BMI. Pregravid body mass index of $\geq 30 \mathrm{mg} / \mathrm{k}^{2}$ (adjOR 3.52, 95\% CI 2.07-5.99) was the strongest predictor of GDM [Table 2]. Use of 17-OHPC did not modify the risk of GDM (adjOR 1.04 95\% CI 0.62-1.73). Because screening for gestational diabetes is usually performed between 24 and 28 weeks, we also analyzed the incidence of gestational diabetes for deliveries after 28 weeks of gestation in order to capture the majority of diagnoses. We found that 17-OHPC was also not associated with gestational diabetes if this diagnosis was made by 28 weeks (adjOR 1.00, 95\% CI 0.61-1.67).

\section{COMMENT}

Our study shows that administration of 17-OHPC to both singleton and twin pregnancies did not increase the rate of gestational diabetes. The rate of gestational diabetes in our study is consistent with the current national estimate of 5\%. ${ }^{12}$ Traditional risk factors such as maternal BMI and age, rather, continued to be associated with an increased risk for GDM.

Historically, we have associated the hormonal changes associated with pregnancy, particularly increasing levels of estrogen and progesterone, with insulin resistance. Picard and colleagues have shown that progesterone accelerates the progression of gestational diabetes in a study using progesterone receptor knock-out mice. ${ }^{7}$ They also showed that administration of an 
antagonist to the progesterone receptor, RU-486, reduced blood glucose levels. Recent data suggest, however, that estrogen and progesterone are protective against insulin resistance. Margolies et al. found that postmenopausal women on estrogen and progesterone were less likely to develop diabetes than women not taking these hormones. ${ }^{13}$ Investigators have actually sought to use these hormones to prevent the onset of insulin resistance in an animal model. ${ }^{14}$

Our results were different than those of Rebarber and colleagues. ${ }^{8}$ As in their study, our data were also collected prospectively. The data gathered by the Maternal-Fetal Medicine Units are collected by trained research staff on detailed data forms. Patients in both arms of the singleton and twin studies were seen weekly by research staff with ongoing data collection. Because our data were gathered as part of one of two randomized, double-blind, placebo-controlled trials, the possibility of bias is greatly decreased. By design, an RCT results in 2 groups of patients with similar characteristics, limiting the chance of selection bias, while the double-blinding ensures that the provider and patient are unaware of the treatment assignment, limiting systemic bias. Those receiving placebo were monitored as closely as those receiving study drug. The study by Rebarber et al. was observational, therefore by design the possibility for selection bias (which women received 17-OHPC) and ascertainment bias (which women were tested and diagnosed for gestational diabetes) exists. It is unclear which co-morbidities allowed for the controls to be entered into the Matria database since these patients were not receiving placebo. It is also not clear whether the patient provider or the Matria staff collected the patient data, and whether data were collected at regular time intervals bringing into question the data ascertainment.

The limitations of this study warrant discussion. This is a secondary analysis of two separate studies. The diagnosis of GDM was chart abstracted; information was not provided regarding timing of GDM testing or criteria used for the diagnosis of GDM. Prior obstetrical information including GDM in a previous pregnancy or history of macrosomia was also not included. While we cannot ascertain how GDM was diagnosed, we do know that there is not a wide variation in criteria used for this diagnosis amongst the centers involved in this study. Additionally, there were some differences amongst the patients from either study. The most important difference was the higher percent of African-Americans in the preterm birth prevention study compared to the twin study since African-American race influences the development of GDM. However, race was controlled for in the logistic regression model, and our findings remained consistent. The strengths of this study are the large numbers of patients included for analysis. We included two separate randomized controlled trials, yet they have similar results. Finally, as mentioned previously, the RCT design limits our likelihood for selection and systemic bias.

We did not perform a post-hoc power analysis, as this practice is not deemed appropriate in the setting of a fixed sample size, such as in the case of secondary analyses. Our point estimate for the association of 17-OHPC with GDM of 1.04 along with our $95 \%$ confidence intervals suggest that there was not an association between the two.

Progesterone has many recognized effects on the myometrium, including preventing formation of gap junctions, decreasing oxytocin receptors, and decreasing conductance of contractions, that may mediate the decrease in preterm birth in women at risk, but the exact mechanism of action is unknown. ${ }^{15}$ Progesterone is also a recognized anti-inflammatory, which is why investigators are now evaluating its use for women with a short cervix. ${ }^{16,17}$ ACOG has cautioned that research should be performed before expanding the indication of this drug. ${ }^{5}$ Similarly, collecting data on the potential complications associated with its use, such as the data on GDM collected in this study, should continue as the use of progesterone becomes common practice. 
In conclusion weekly administration of 17-OHPC is not associated with higher rates of gestational diabetes in either singleton or twin pregnancies. Women using progesterone during pregnancy needn't undergo glucose tolerance screening outside of standard testing unless additional risk factors are present.

\section{Acknowledgments}

Supported by grants from the Eunice Kennedy Shriver National Institute of Child Health and Human Development (HD27869, HD21410, HD40512, HD34136, HD34208, HD40485, HD27915, HD40544, HD40560, HD27917, HD40500, HD34116, HD40545, HD27860, HD36801, HD21414, HD34122, HD27905, HD34210, HD27861)

\section{Appendix}

The authors wish to acknowledge subcommittee members who contributed as follows: Mark A. Klebanoff, M.D (protocol development and oversight), Elizabeth Thom, $\mathrm{PhD}$ (protocol development, data management and statistical analysis), Allison Northen, RN, Margaret Cotroneo, RN, and Melissa Swain, RN (protocol development and coordination between clinical research centers).

In addition to the authors, other members of the Eunice Kennedy Shriver National Institute of Child Health and Human Development Maternal-Fetal Medicine Units Network are as follows:

Columbia University - R. Berkowitz, F. Malone, S. South, L. Paley, S. Bousleiman, V. Carmona, M. D'Alton, V. Pemberton

University of North Carolina - J. Thorp, K. Boggess, K. Dorman, S. Timlin, K. Moise University of Alabama at Birmingham - W. Andrews, J. Sheppard, A. Northen, J. Hauth University of Pittsburgh - E. Daugherty, M. Cotroneo, H. Simhan, K. Lain

Northwestern University — M. Dinsmoor (Evanston Hospital), G. Mallett, P. Simon, M. Huntley, M. Ramos, M. Socol

Drexel University - M. DiVito, M. Hoffman, S. Wilson, C. Tocci, M. Lake, M. Talucci

University of Utah -K. Anderson (University of Utah Health Sciences Center), F. Porter (Intermountain Healthcare), A. Guzman (McKay-Dee Hospital Center), K. Jolley (Utah Valley Regional Medical Center), S. Quinn (LDS Hospital), M. Belfort (Utah Valley Regional Medical Center), E. Taggart (University of Utah Health Sciences Center)

The Ohio State University - F. Johnson, C. Latimer, M. Landon

Case Western Reserve University - C. Milluzzi, C. Heggie, H. Ehrenberg, B. Stetzer, A. Merlino, P.Catalano

Wayne State University - Y. Sorokin, G. Norman, C. Sudz, S. Blackwell

Brown University - D. Allard, H. Silver, J. Tillinghast

University of Texas Southwestern Medical Center - K. Leveno, L. Moseley

University of Texas Health Sciences Center at Houston - D. Soebbing-Cross, J. Martinez, B. Glenn-Cole, L. Gilstrap, M. C. Day

University of Tennessee - R. Ramsey

University of Miami - C. Alfonso, S. Beydoun

University of Cincinnati - N. Elder, T. Siddiqi

University of Texas at San Antonio - O. Langer, S. Nicholson 
University of Chicago - A. Moawad, P. Jones M. Lindheimer

Wake Forest University Health Sciences - M. Harper, M. Swain, K. Johnson, K. Lanier, C. Leftwich, E. Mueller-Heubach

The George Washington University Biostatistics Center - E. Thom, L. Leuchtenburg, A. Das

Eunice Kennedy Shriver National Institute of Child Health and Human Development M. Klebanoff, S. Pagliaro, D. McNellis.

Steering Committee Chair - G. Anderson - University of Texas Medical Branch, Galveston, $T X$

\section{REFERENCES}

1. Mattison DR, Damus K, Fiore E, Petrini J, Alter C. Preterm delivery: a public health perspective. Paediatr Perinat Epidemiol 2001;15:7-16. [PubMed: 11520396]

2. Creasy RK. Preterm birth prevention: Where are we? Am J Obstet Gynecol 1993;168:1223-1230. [PubMed: 8475969]

3. Meis PJ, Klebanoff M, Thom E, et al. Prevention of recurrent preterm delivery by 17 alphahydroxyprogesterone caproate. N Engl J Med 2003;348:2379-2385. [PubMed: 12802023]

4. da Fonseca EB, Bittar RE, Carvalho MH, Zugaib M. Prophylactic administration of progesterone by vaginal suppository to reduce the incidence of spontaneous preterm birth in women at increased risk: a randomized placebo-controlled double-blind study. Am J Obstet Gynecol 2003;188:419-424. [PubMed: 12592250]

5. American College of Obstetricians and Gynecologists Committee Opinion. Use of progesterone to prevent preterm birth. Number 419, October 2008. Obstet Gynecol 2008;112:963-965. [PubMed: 18827143]

6. Branisteanu DD, Mathieu C. Progesterone in gestational diabetes mellitus: guilty or not guilty? Trends Endocrinol Metab 2003;14:54-56. [PubMed: 12591170]

7. Picard F, Wantabe M, Schoonjans K, Lydon J, O’Malley BW, Auwerx J. Progesterone receptor knockout mice have an improved glucose homeostasis secondary to beta -cell proliferation. Proc Natl Acad Sci U S A 2002;99:15644. [PubMed: 12438645]

8. Rebarber A, Istwan NB, Russo-Stieglitz K, et al. Increased incidence of gestational diabetes in women receiving prophylactic 17 Alpha-hydroxyprogesterone caproate for prevention of recurrent preterm delivery. Diabetes Care 2007;30:2277-2280. [PubMed: 17563346]

9. Kjos SL, Buchanan TA. Gestational diabetes mellitus. N Engl J Med 1999;341:1749-1756. [PubMed: 10580075]

10. Buhling KJ, Henrich W, Starr E, et al. Risk for gestational diabetes and hypertension for women with twin pregnancy compared to singleton pregnancy. Arch Gynecol Obstet 2003;269:33-36. [PubMed: 12682848]

11. Rouse DJ, Caritis SN, Peaceman AM, et al. A trial of 17 alpha-hydroxyprogesterone caproate to prevent prematurity in twins. N Engl J Med 2007;357:454-461. [PubMed: 17671253]

12. American College of Obstetricians and Gynecologists Committee on Practice Bulletins- Obstetrics: ACOG Practice Bulletin: Gestational diabetes. Number 30. 2001 September;93:525-538.

13. Margolies KL, Bonds DE, Rodabough RH, et al. Effect of oestrogen plus progestin on the incidence of diabetes on postmenopausal women: results from the Women's Health Initiative Hormone Trial. Diabetologia 2004;47:1175-1187. [PubMed: 15252707]

14. Ordonez P, Moreno M, Alonso A, Llaneza P, Diaz F, Gonzalez C. 17 beta-estradiol and/or progesterone protect from insulin resistance in STZ-induced diabetic rats. J Steroid Biochem Mol Biol 2008;111:287-294. [PubMed: 18657616]

15. Spong CY. Prediction and prevention of recurrent spontaneous preterm birth. Obstet Gynecol 2007;110:405-415. [PubMed: 17666618] 
16. Fonseca EB, Celik E, Parra M, Singh M, Nicolaides KH. Fetal Medicine Foundation Second Trimester Screening Group. Progesterone and the risk of preterm birth among women with a short cervix. N Engl J Med 2007;357:462-469. [PubMed: 17671254]

17. DeFranco EA, O'Brien JM, Adair CD, et al. Vaginal progesterone is associated with a decrease in risk for early preterm birth and improved neonatal outcome in women with a short cervix: a secondary analysis from a randomized, double-blind, placebo-controlled trial. Ultrasound Obstet Gynecol 2007;30:697-705. [PubMed: 17899571] 


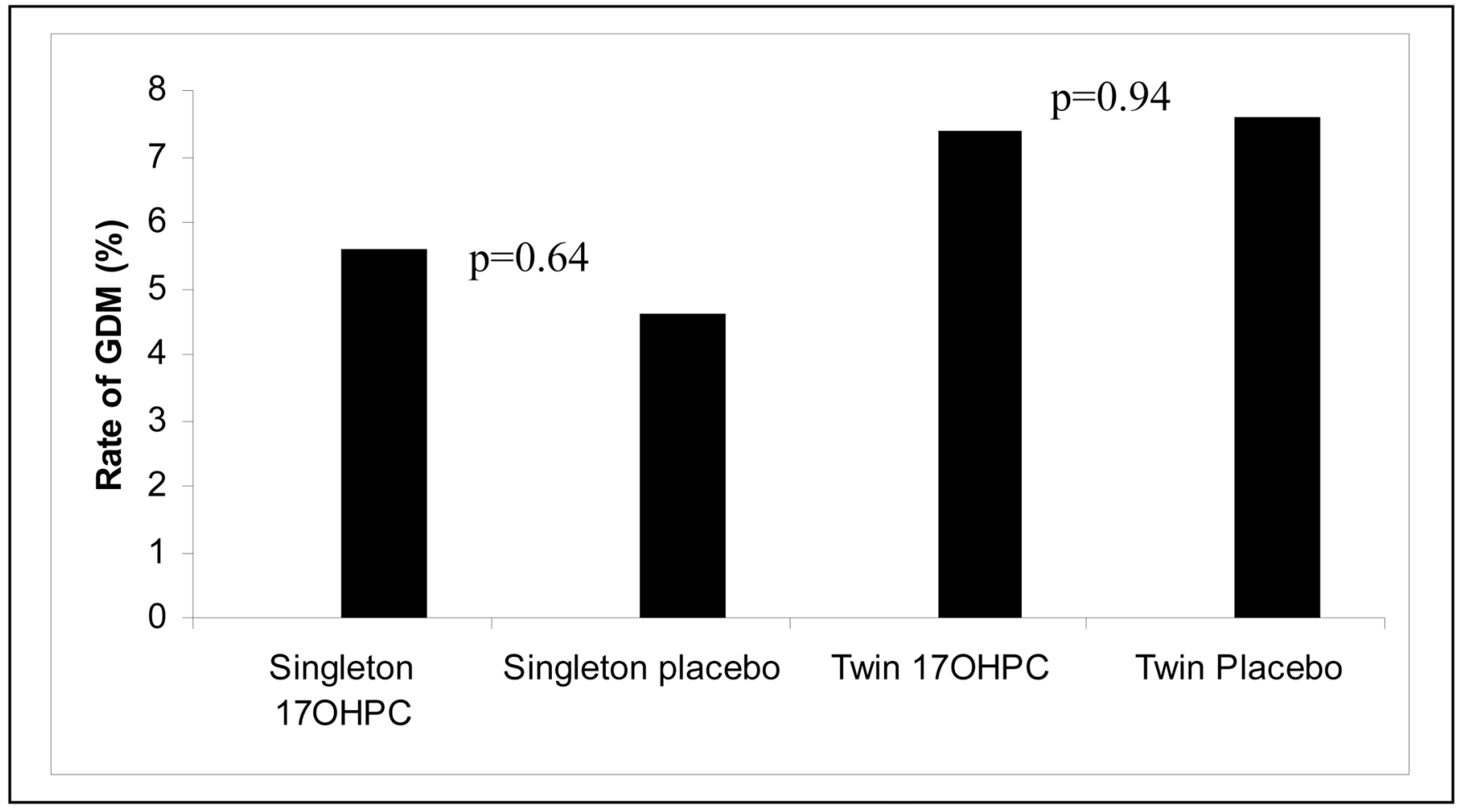

Figure 1.

Rates of GDM among Treatment and Placebo Patients 


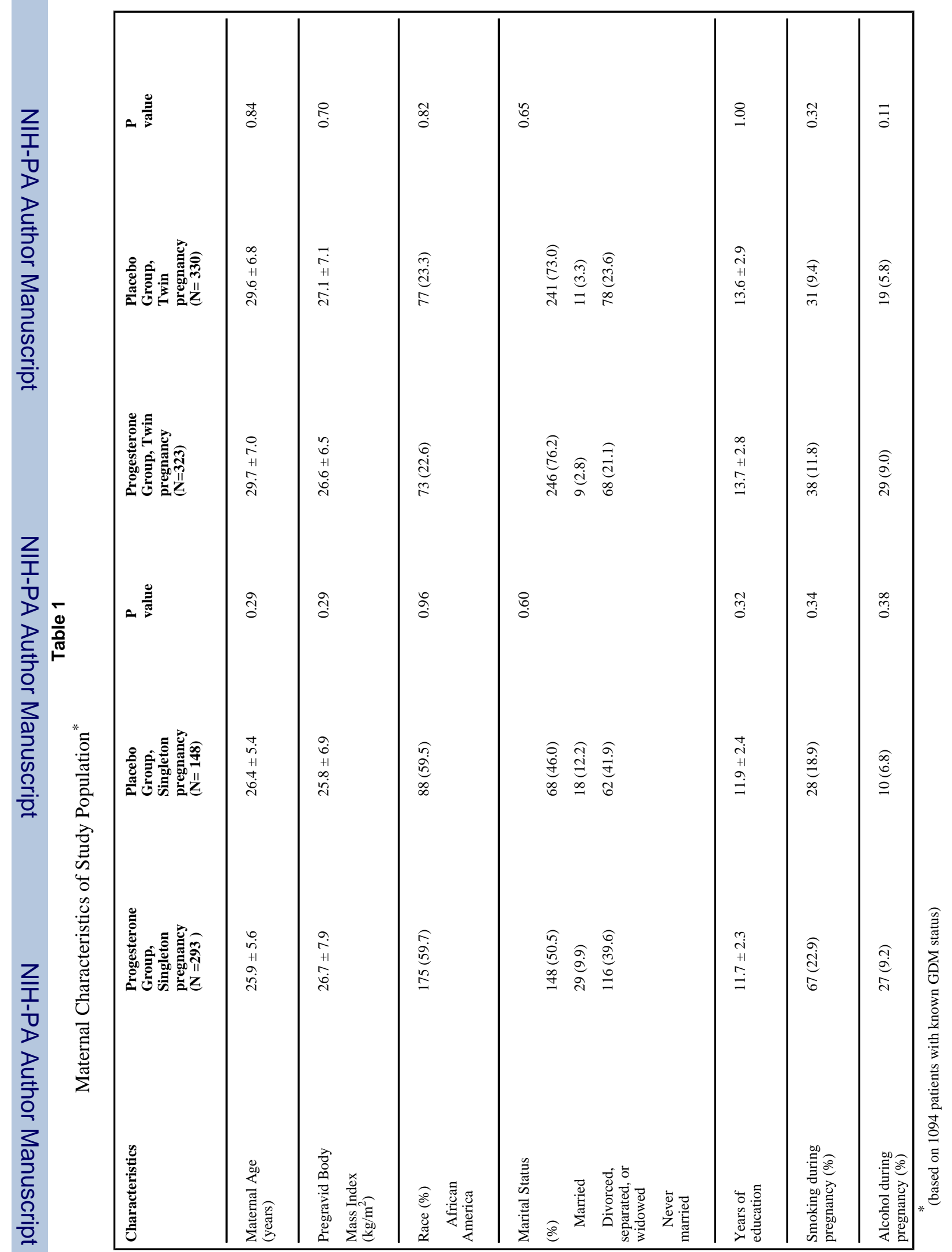

Am J Obstet Gynecol. Author manuscript; available in PMC 2010 October 1. 
Table 2

Maternal Characteristics, Study Group, Treatment and Risk for GDM

\begin{tabular}{|c|c|c|}
\hline & $\operatorname{adjOR}$ & 95\% CI \\
\hline Maternal Age (yrs) & 1.11 & $1.06-1.15$ \\
\hline Obesity (BMI $\geq 30 \mathrm{~kg} / \mathrm{m} 2$ ) & 3.52 & $2.07-5.99$ \\
\hline Twin Pregnancy & 0.97 & $0.53-1.77$ \\
\hline African-American Race & 1.05 & $0.56-1.94$ \\
\hline 17-OHPC Use & 1.04 & $0.62-1.73$ \\
\hline
\end{tabular}

